\section{Estudo da fluxibilidade em areias de moldagem a verde}

\author{
Study on the flowability of the Green \\ Sand Molding
}

\author{
Vanessa Mais ${ }^{1}$, Wilson Luis Guesser², \\ Isaías Masiero $^{3}$
}

\author{
1,2,3 Universidade Estadual de Santa Catarina - UDESC - Campus Universitário Professor Avelino Marcante, s/n - 89223 \\ -100 , Joinville - SC. \\ e-mail: vanessam@tupy.com.br; wlguesser@uol.com.br; imasiero@masiero.org.
}

\section{RESUMO}

Descreve-se um estudo realizado sobre a fluxibilidade das areias de moldagem a verde com o objetivo de quantificar a influência do grau de compactação e das propriedades da mistura sobre a escoabilidade. Para este trabalho foram escolhidos dois métodos: um denominado como TNO (fluxibilidade sob queda) que mede a facilidade ou não com que a areia ultrapassa alguns orifícios presentes em um dispositivo e o método Orlov (fluxibilidade sob compactação) que quantifica a relação entre a dureza do corpo de prova nas regiões de difícil e fácil compactação. Os resultados demonstraram que o método TNO é sensível as mudanças de compactabilidade da areia, mas não possui correlação com as variações da quantidade e tipo de bentonita. . Já o método Orlov demonstra ter correlação, sendo menor a fluxibilidade em misturas com alto teor de compactabilidade, menor tamanho médio da areia base e maior quantidade e uso de bentonita sódica natural. Além disso, verificou-se também que em maiores níveis de compactação ocorre menor variação de fluxibilidade entre as composições. Portanto, pode-se se dizer que a utilização conjunta destes dois métodos de medição da fluxibilidade possibilita prever o comportamento da areia de moldagem a verde tanto durante o enchimento da caixa de moldar (TNO), como durante a compactação (Orlov).

Palavras-chave: fluxibilidade, areia a verde, moldagem, bentonita.

\section{ABSTRACT}

It is described a study on the flowability of the green sand molding quantifying the influence of the degree of compaction and the properties of the mixture on the flowability. In this work two methods were chosen. One is denominated TNO which measures the difficulty of the sand grain to pass through a device's opening and the other method is called Orlov, which quantifies the relationship between the hardness of the test piece in areas of high and low levels of compaction. The results demonstrated that the TNO method is sensitive to changes in the sand compactability, but has no correlation with the variations in the amount and type of bentonite. However, the Orlov method shows that a lower flowability is achieved in mixtures with a high level of compactibility, lower average size of the sand and use of greater amounts of natural sodium bentonite. Besides that, it was found that at higher levels of compactability, there is a lower flowability variation between compositions So, it can be concluded that the combined use of these two methods of flowability measurement allows to forsee the behavior of the green sand not only during the filling of the mould (TNO) but also during the compression (Orlov).

Keywords: flowability, green sand, molding, bentonite.

\section{INTRODUÇÃO}

Dentre as diversas técnicas de fundição, o processo de moldagem em areia a verde é o mais empregado na produção de peças acabadas. As principais razões para isso são a boa flexibilidade, produtividade e qualidade, assim como a economia de matéria-prima [1]. O principal componente da areia de moldagem é um agre- 
PICANÇO, M.S.; ANGÉLICA, R.S.; B ARATA, M.S. revista Matéria, v.19, n.02, pp. 94-104, 2014.

gado fino, mineralogicamente considerado puro, denominado "areia base" ao qual é misturado um agente aglomerante, água e outros aditivos como, por exemplo, o pó de carvão, que conferem propriedades específicas à mistura. $\mathrm{O}$ aglomerante mais utilizado é a bentonita, caracterizada como uma argila plástica constituída por argilominerais do grupo das esmectitas (montmorilonítica), responsável pela coesão da areia quando umidificada, proporcionando resistência ao molde [2, 3] $]$. Logo após a preparação da areia de moldagem, ocorre a confecção do molde através do preenchimento e compactação da areia sobre o modelo contendo a geometria externa da peça [2, 4]. Existem tecnologias diferenciadas de compactação de moldes sendo que a forma com que o molde é adensado pode impactar diretamente na qualidade do fundido.

Em virtude do crescimento do uso das máquinas de alta pressão nas fundições, o estudo sobre a influência das características da areia de moldagem na energia necessária para compactar o molde tornou-se ainda mais importante neste processo. Em laboratório, é possível correlacionar as propriedades da mistura com o grau de adensamento através do ensaio de fluxibilidade ou também chamado de escoabilidade.

Em geral, a fluxibilidade é considerada como a habilidade relativa da areia de moldagem se comportar como um fluido. Entretanto alguns autores a denominaram como a habilidade dos grãos de areia de se movimentar uns contra os outros através da aplicação de uma força de compressão, proporcionando na superfície do molde uma dureza mais uniforme [5]. A maior movimentação dos grãos ocorre através da deformação das regiões entre a areia e a bentonita, ou seja, por meio da redução da força de adesão e coesão $[\underline{5}, \underline{6}, \underline{7}]$.

Maiores valores de umidade e quantidade de bentonita geram uma restrição ao movimento dos grãos de areia de moldagem, dificultando o adensamento. $\mathrm{O}$ tipo de bentonita também influencia na escoabilidade, sendo menor quando utilizadas argilas que proporcionam maior plasticidade à mistura $[2,8]$.

No caso das areias de moldagem preparadas em tempos de mistura prolongados, ocorre aumento nas áreas de ligação entre a bentonita e a superfície dos grãos fazendo crescer igualmente as forças coesivas e adesivas. As características granulométricas e o formato dos grãos de areia empregados na mistura influenciam na fluxibilidade. Esse efeito também é explicado através das forças adesivas que tem que ser vencidas para se promover a compactação, sendo consequência da espessura e da qualidade dos filmes de bentonita umedecidos que recobrem os grãos. Desta maneira, quanto maior o número de contatos entre grãos, isto é, maiores pontos de aplicação de força adesiva, menor a fluxibilidade. Na medida em que se diminui o tamanho médio dos grãos de areia (areias mais finas), eleva-se o número de pontos de contato, reduzindo a escoabilidade [2].

A procura por ensaios em laboratório cada vez mais sensíveis às influências da composição e parâmetros da mistura sobre a fluxibilidade da areia perdura por várias décadas [4]. Em decorrência disto, diversos ensaios de fluxibilidade foram criados tendo destaque os métodos TNO e Orlov. O ensaio de fluxibilidade TNO consiste em uma medição do percentual de areia de moldagem que ultrapassa alguns orifícios presentes em um dispositivo, já o ensaio de fluxibilidade Orlov faz a quantificação da relação entre a dureza do corpo de prova nas regiões de difícil (B) e fácil (A) compactação [9].

Com base no que foi anteriormente exposto, este trabalho tem como objetivo comparar a fluxibilidade com diferentes composições de areia de moldagem a verde, através de variações de compactabilidade obtidas por quantidades crescentes de água na mistura, quantidade e tipo de bentonita, além do tempo de mistura e o grau de compactação. Para isso foram utilizados os métodos de medição de fluxibilidade TNO e Orlov.

\section{MATERIAIS E MÉTODO}

\subsection{Preparação das misturas}

Para a realização dos ensaios de fluxibilidade TNO e Orlov, utilizou-se os componentes da mistura caracterizados na tabela 1. As misturas foram preparadas em laboratório por meio de um misturador de mós verticais modelo ML-7, tipo Simpson, com capacidade de preparação de $7 \mathrm{Kg}$ de areia, sendo primeiramente adicionada a areia base + água por 1 min. e posteriormente a bentonita e o pó de carvão por mais 14 minutos. $\mathrm{O}$ tempo de homogeneização foi de 60 minutos, avaliando a fluxibilidade em relação ao tempo de mistura. Em todas as composições foi adicionado $1 \%$ de pó de carvão. Como complemento, analisaram-se as areias de moldagem preparadas quanto aos ensaios de compactabilidade (\%), umidade $(\%)$, permeabilidade $(\mathrm{cm} 4 \mathrm{~g}$ ${ }^{1}$ min-1), resistência à compressão a verde $\left(\mathrm{N} / \mathrm{cm}^{2}\right)$ e resistência à tração a úmido $\left(\mathrm{N} / \mathrm{cm}^{2}\right)$, recomendado pela CEMP e submetido à norma $\mathrm{ABNT}$. 
PICANÇO, M.S.; ANGÉLICA, R.S.; B ARATA, M.S. revista Matéria, v.19, n.02, pp. 94-104, 2014.

Tabela 1: Caracterização dos componentes das misturas utilizados.

\begin{tabular}{|c|c|c|}
\hline Características & \multicolumn{2}{|c|}{ Matéria-prima } \\
\hline Areia Base & SAG & SAF \\
\hline Teor de argila AFS (\%) & 0,13 & 0,22 \\
\hline Módulo de finura (AFS) & 56,21 & 81,57 \\
\hline Teor de finos $(\%)$ & 1,30 & 4,82 \\
\hline Coeficiente de angularidade & 1,60 & - \\
\hline Demanda ácida pH 2 & 4,50 & 3,8 \\
\hline Demanda ácida pH 6 & 0,20 & 0,50 \\
\hline Bentonita & $\mathrm{BNa}$ & $\mathrm{BCa}$ \\
\hline Umidade $(\%)$ & 11,7 & 12,0 \\
\hline Absorção de azul de metileno (ml) & 56,0 & 53,6 \\
\hline Teor de partículas grossas (malha 200) (\%) & 9,8 & 3,50 \\
\hline Inchamento $(\mathrm{ml})$ & 31 & 38 \\
\hline Estabilidade térmica $\left(550^{\circ} \mathrm{C}\right)(\%)$ & 73,21 & 62,07 \\
\hline Pó de carvão & \multicolumn{2}{|c|}{$\mathrm{PC}$} \\
\hline Umidade (\%) & \multicolumn{2}{|c|}{4,5} \\
\hline Cinzas (\%) & \multicolumn{2}{|c|}{12,40} \\
\hline Enxofre (\%) & \multicolumn{2}{|c|}{1,12} \\
\hline Voláteis (\%) & \multicolumn{2}{|c|}{37,93} \\
\hline Retido na peneira $-12(1,68 \mathrm{~mm})(\%)$ & \multicolumn{2}{|c|}{0,00} \\
\hline Retido na peneira - $200(0,074 \mathrm{~mm})(\%)$ & \multicolumn{2}{|c|}{60,18} \\
\hline Retido no prato - (\%) & \multicolumn{2}{|c|}{39,82} \\
\hline
\end{tabular}

\subsection{Ensaios de fluxibilidade}

Os resultados de fluxibilidade TNO foram obtidos através de um dispositivo, conforme descrito na figura 1, no qual foi adicionado $400 \mathrm{~g}$ de areia preparada em um funil, localizado na parte superior do equipamento. Uma comporta posicionada no fundo deste funil foi aberta a cada ensaio, fazendo com que a areia fosse lançada em direção aos orifícios presentes no fundo do dispositivo. O valor de fluxibilidade TNO é dado pela diferença em percentual entre a quantidade de areia inicial e a quantidade que atravessa estes orifícios. Para cada mistura mediu-se duas amostras de fluxibilidade TNO.

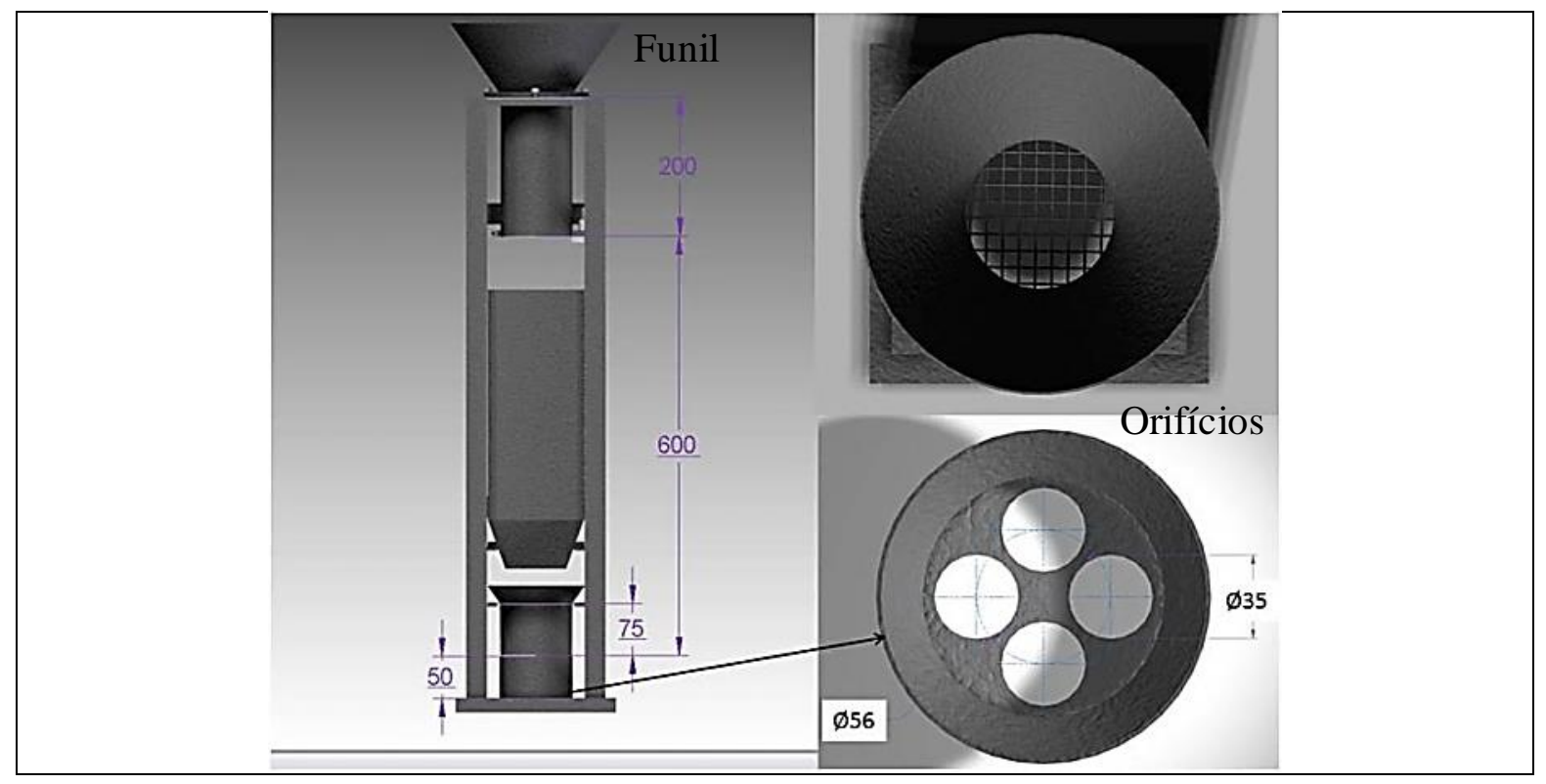


PICANÇO, M.S.; ANGÉLICA, R.S.; B ARATA, M.S. revista Matéria, v.19, n.02, pp. 94-104, 2014.

Figura 1: Dispositivo TNO utilizado para medir a fluxibilidade sob queda da areia de moldagem.

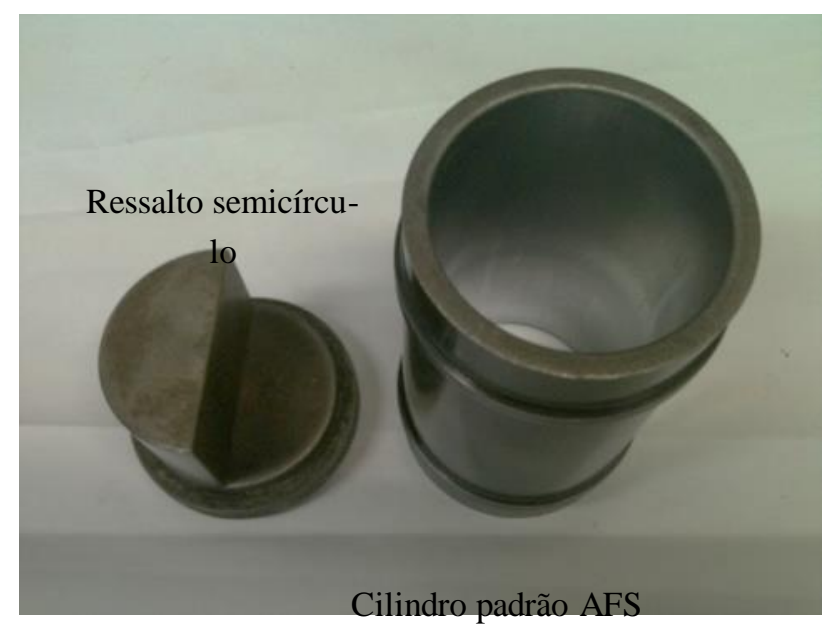

Figura 2: Ressalto na base do cilindro padrão AFS utilizado nas determinações da fluxibilidade Orlov.

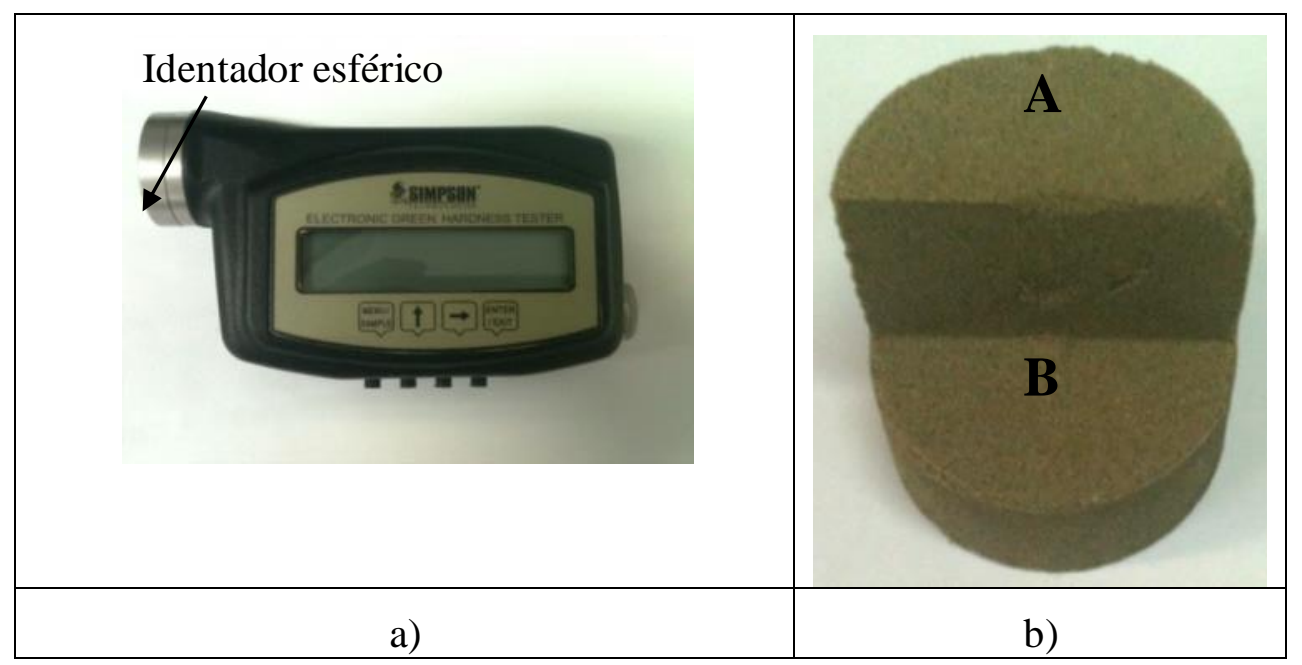

Figura 3: a) Medidor de dureza do molde em areia a verde tipo escala B e b) os pontos de medição da dureza no corpo de prova padrão

\subsection{Análise no microscópio eletrônico de varredura (MEV)}

Confeccionou-se corpos de prova do ensaio de fluxibilidade Orlov com areia preparada em laboratório contendo $10 \%$ de bentonita sódica natural (BNa), $1 \%$ de pó de carvão (PC), areia com módulo de finura de 50/57 AFS (SAG) e a quantidade de água na mistura necessária para obter uma compactabilidade de 50\%. Os corpos de prova foram divididos em duas partes sendo uma da região mais adensada (B) e outra do ponto menos compactado (A).

As amostras foram visualizadas em um microscópio eletrônico de varredura Hitachi modelo TM 3000 (table top microscope EDS), após a aplicação do vácuo, sem necessidade de recobrimento com metal condutor. Analisaram-se as imagens em aumentos de 60 e 180x. 
PICANÇO, M.S.; ANGÉLICA, R.S.; BARATA, M.S. revista Matéria, v.19, n.02, pp. 94-104, 2014.

\section{RESULTADOS}

\subsection{Fluxibilidade TNO variando a composição da mistura}

Os ensaios realizados em areia de moldagem preparada em laboratório, variando a compactabilidade e as quantidades de bentonita mostraram a relação da fluxibilidade TNO com o uso de uma bentonita sódica natural e cálcica ativada. A figura 4 mostra a correlação destas variáveis com valores médios de fluxibilidade sob queda (TNO).

Influência do tipo, quantidade de bentonita e compactabilidade sobre a fluxibilidade TNO

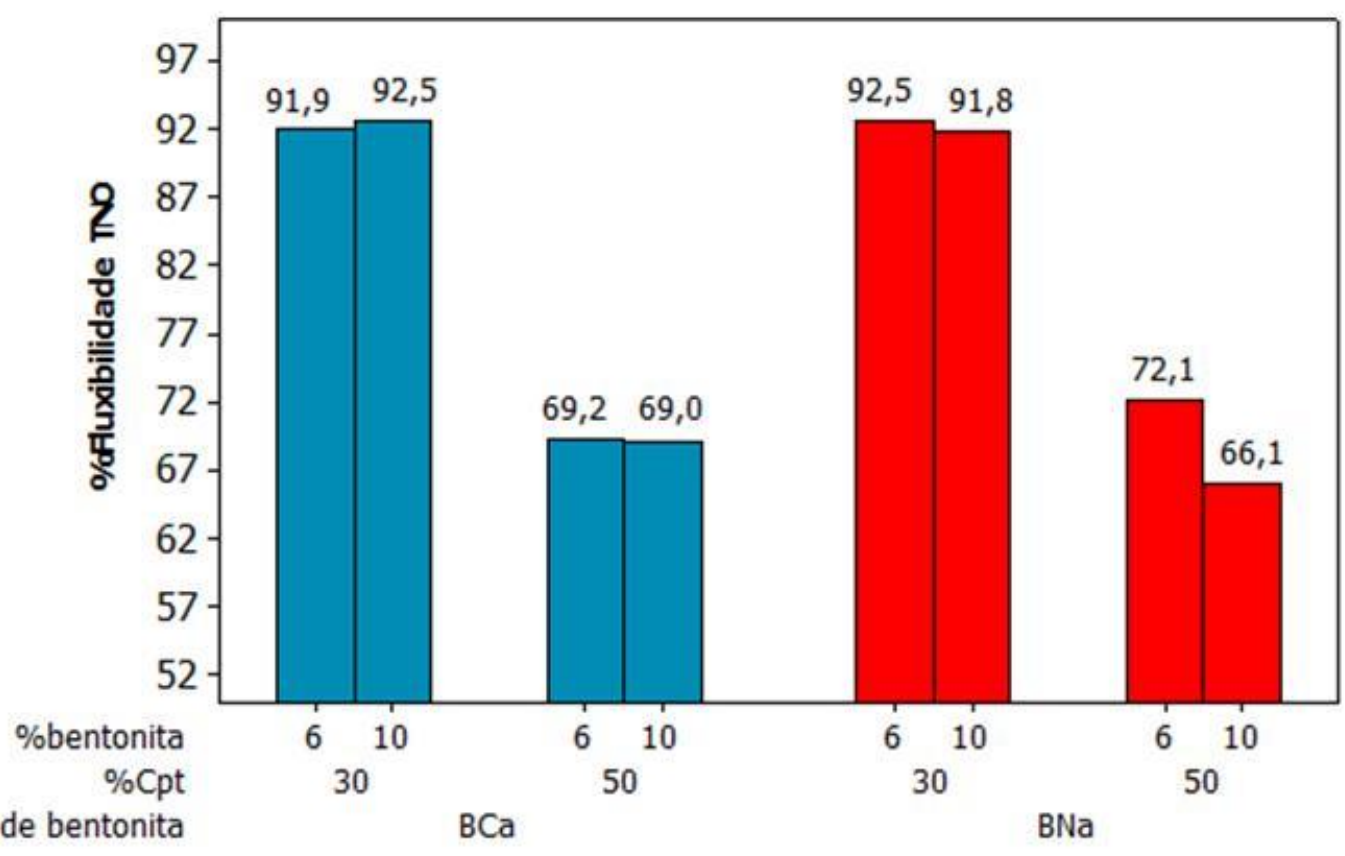

Figura 4: Valores médios da fluxibilidade sob queda (TNO) em função da compactabilidade, teor e tipo de bentonita.

\subsection{Fluxibilidade Orlov variando a composição da mistura}

As figuras 5 a 8 apresentam o efeito da compactabilidade, teor e tipo de bentonita, granulometria da areia base, a influência do tempo de mistura e o grau de adensamento sobre a fluxibilidade Orlov. 
PICANÇO, M.S.; ANGÉLICA, R.S.; BARATA, M.S. revista Matéria, v.19, n.02, pp. 94-104, 2014.

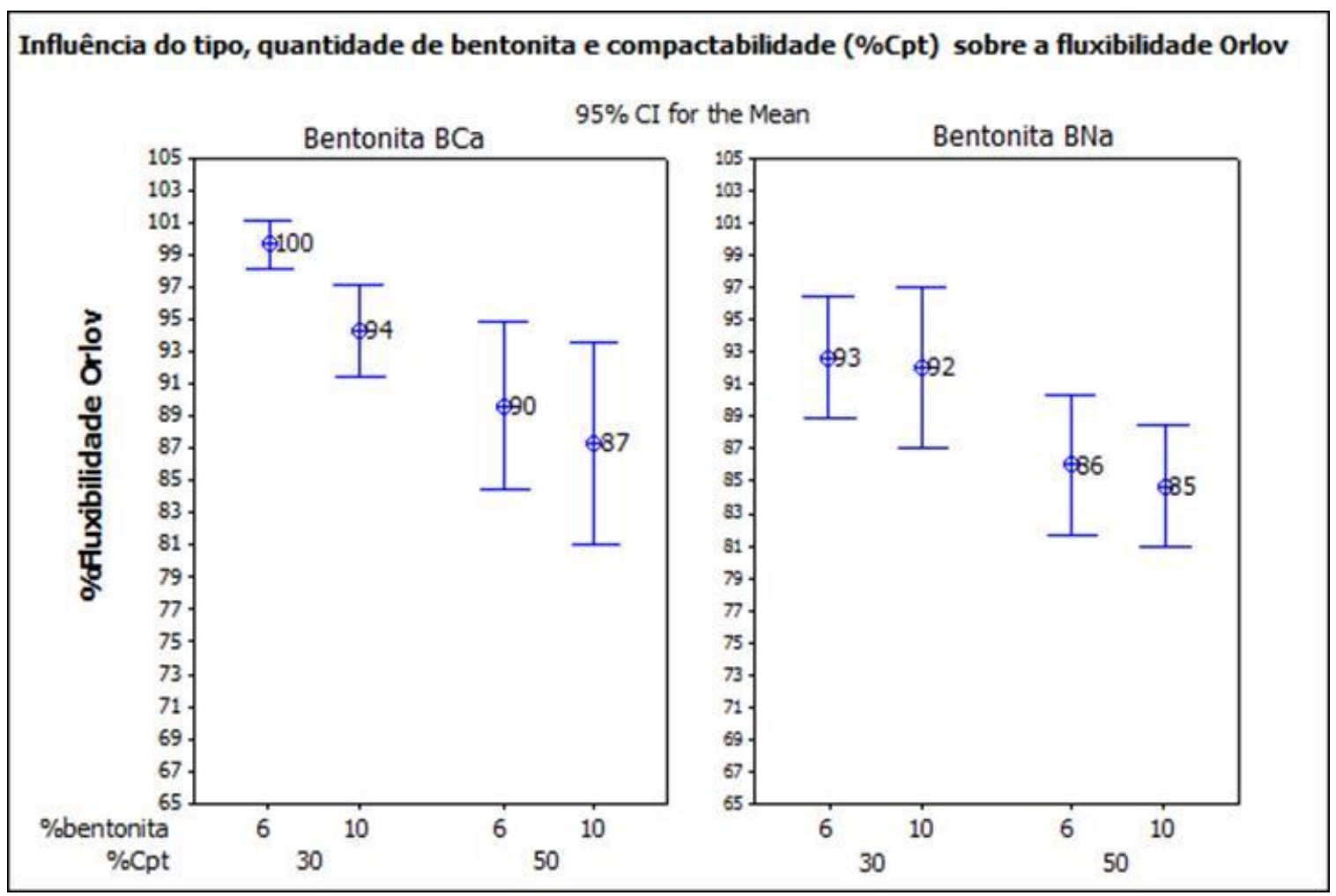

Figura 5: Fluxibilid ade sob compactação (Orlov) em função da compactabilidade, teor e tipo de bentonita

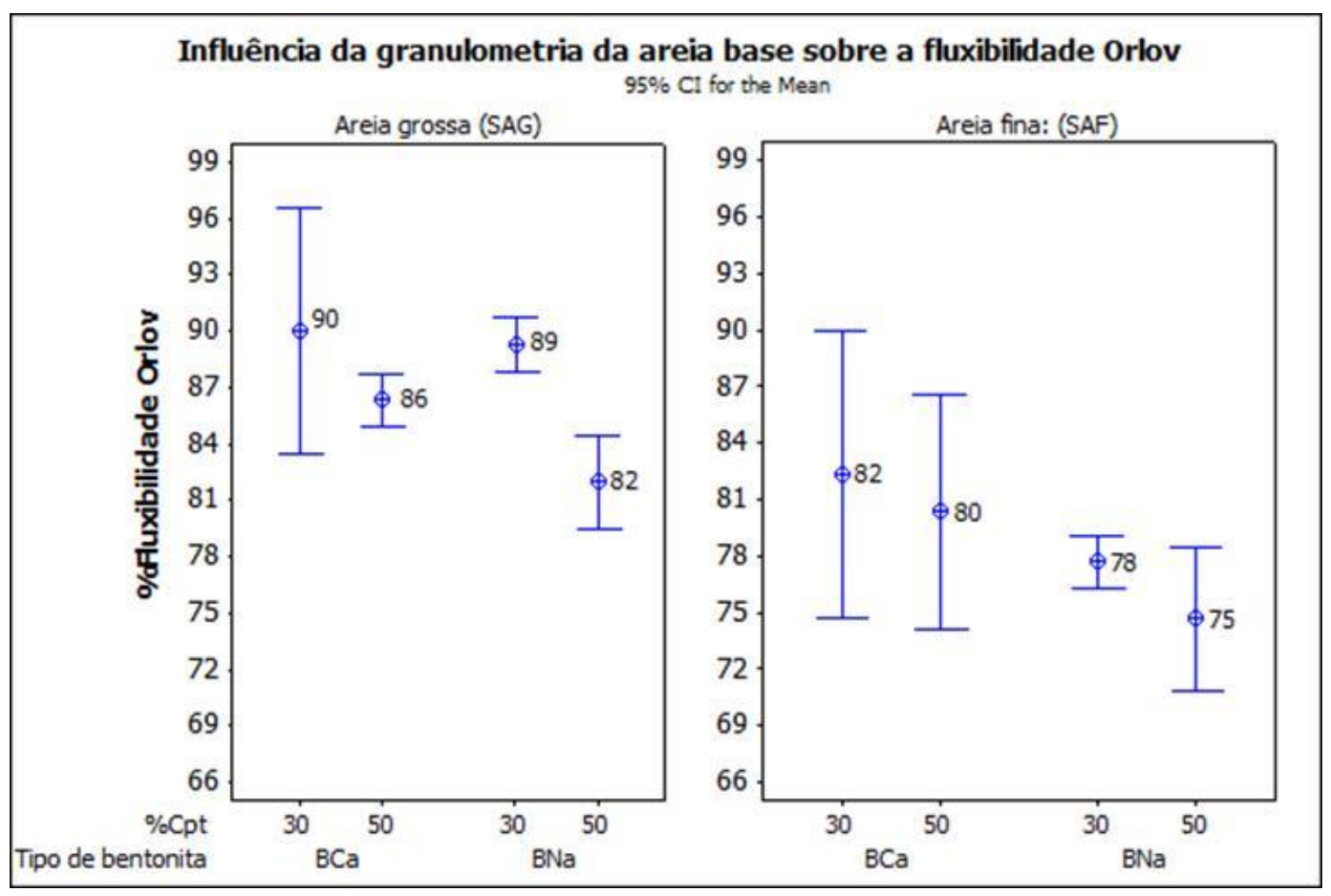

Figura 6: Efeito da granulometria da areia base sobre a fluxibilidade sob compactação (Orlov) para diferentes tipos de bentonita e compactabilidade (misturas contendo $8 \%$ bentonita). 


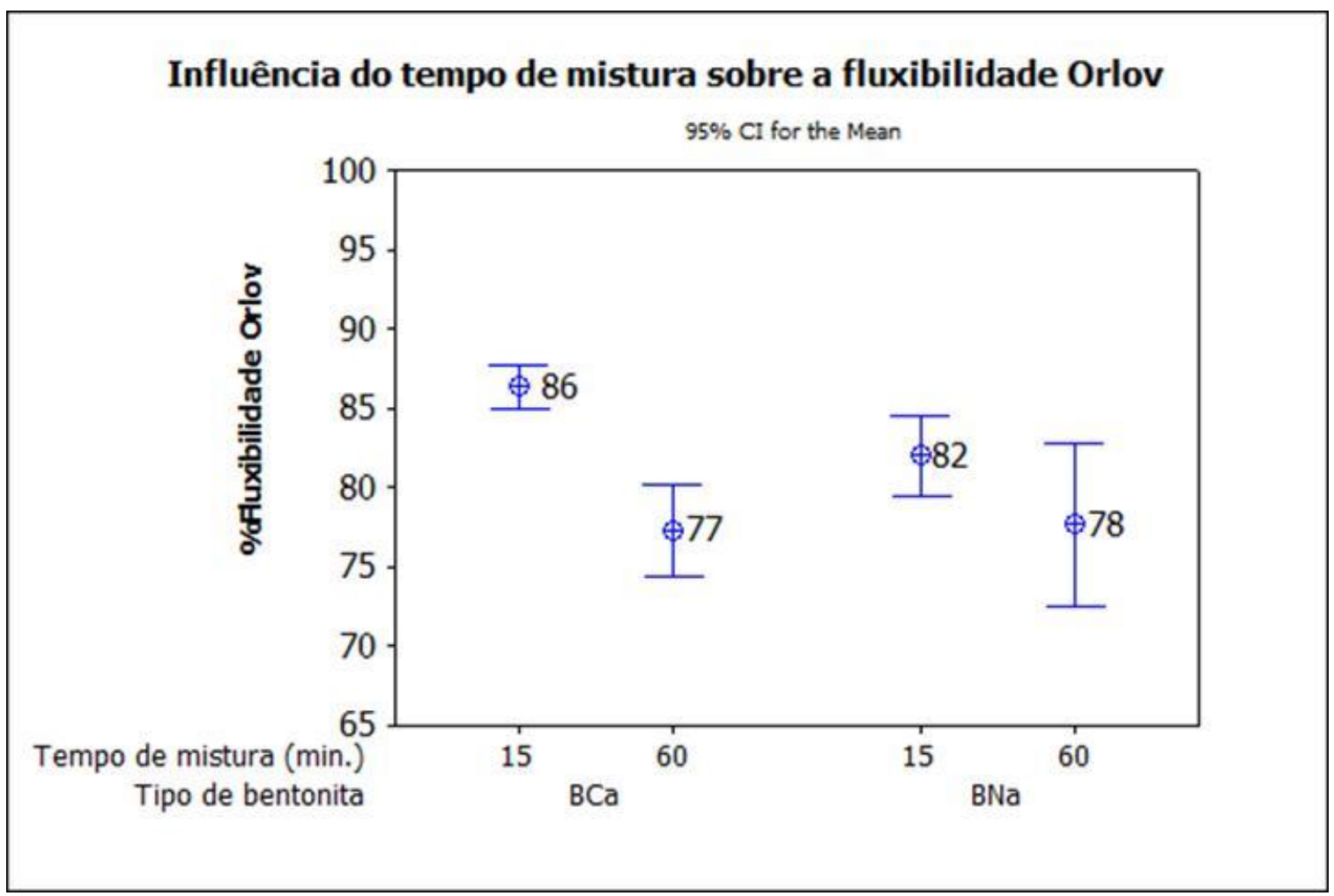

Figura 7: Variação da fluxibilidade Orlov em função do tempo de mistura para diferentes tipos de bentonita (misturas contendo $6 \%$ bentonita).

\subsubsection{Fluxibilidade Orlov variando a composição da mistura}

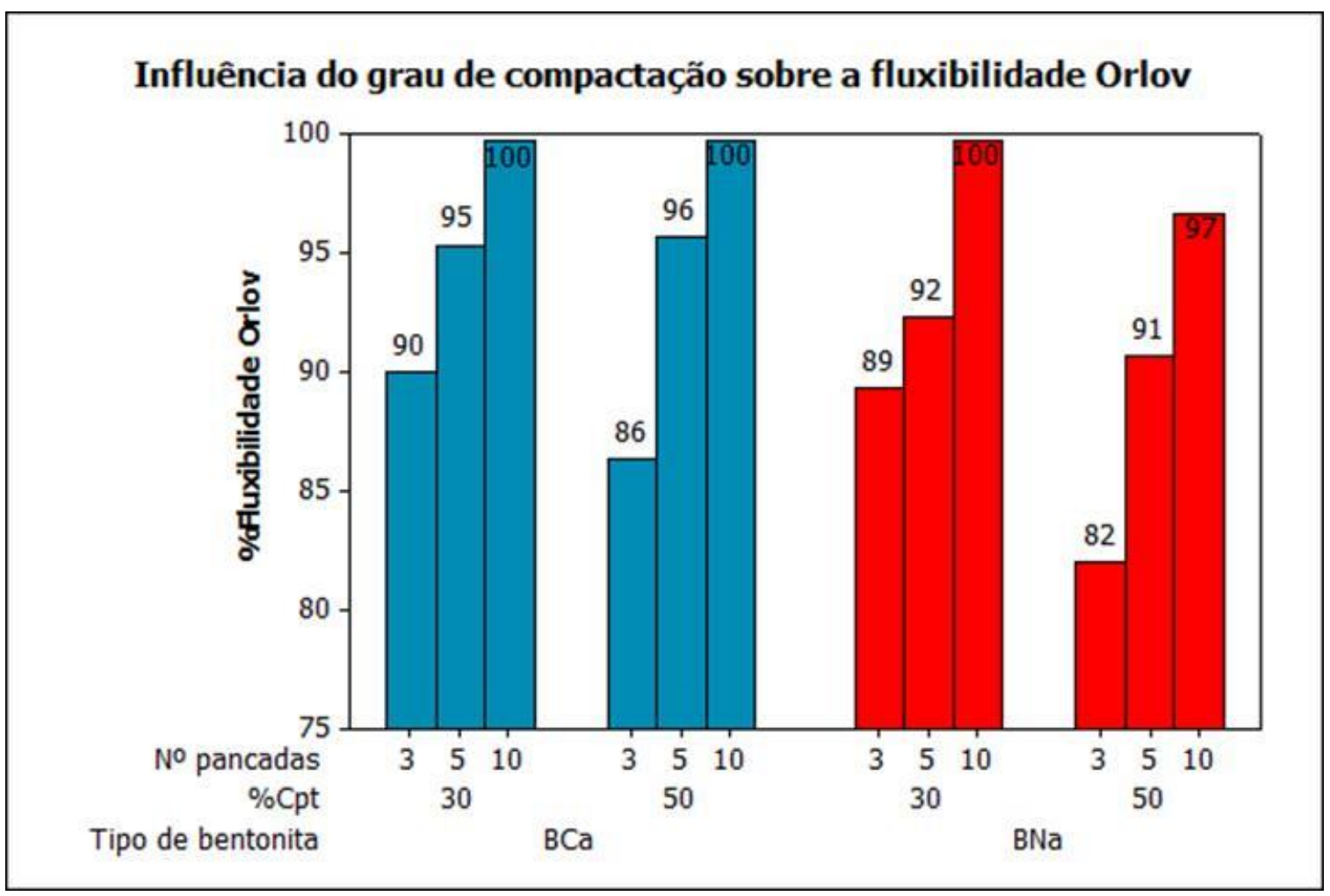

Figura 8: Influência dos diferentes níveis de compactação sobre a fluxibilidade Orlov variando a compactabilidade e o tipo de bentonita (misturas contendo $8 \%$ bentonita). 
PICANÇO, M.S.; ANGÉLICA, R.S.; BARATA, M.S. revista Matéria, v.19, n.02, pp. 94-104, 2014.

\subsubsection{Propriedades das misturas em areia a verde}

A tabela 2 representa as demais propriedades analisadas de cada estudo para complementar os resultados.

Tabela 2: Propriedades das misturas utilizadas nos experimentos.

\begin{tabular}{|c|c|c|c|c|}
\hline Composição da mistura & $\begin{array}{c}\text { Umidade }(\%) \\
{[\underline{10]}]}\end{array}$ & $\begin{array}{c}\text { Permeabilidade } \\
\left(\mathrm{cm}^{4} \mathrm{~g}^{-1} \mathrm{~min}^{-1}\right) \\
{[11]}\end{array}$ & $\begin{array}{l}\text { Resistência à com- } \\
\text { pressão a verde } \\
\left(\mathrm{N} / \mathrm{cm}^{2}\right)[12]\end{array}$ & $\begin{array}{l}\text { Resistência à tra- } \\
\text { ção a úmido [13] }\end{array}$ \\
\hline $\begin{array}{l}30 \% \mathrm{Cpt}, 6 \% \mathrm{BNa}, \text { areia } \\
\text { SAG }\end{array}$ & 1,8 & 88 & 13,8 & 0,17 \\
\hline $\begin{array}{l}50 \% \mathrm{Cpt}, 6 \% \mathrm{BNa} \text {, areia } \\
\text { SAG }\end{array}$ & 2,0 & 114 & 13,9 & 0,30 \\
\hline $\begin{array}{l}30 \% \mathrm{Cpt}, 10 \% \mathrm{BNa} \text {, areia } \\
\text { SAG }\end{array}$ & 2,5 & 73 & 23,2 & 0,33 \\
\hline $\begin{array}{l}50 \% \mathrm{Cpt}, 10 \% \mathrm{BNa} \text {, areia } \\
\text { SAG }\end{array}$ & 2,9 & 104 & 22,2 & 0,41 \\
\hline $\begin{array}{l}30 \% \mathrm{Cpt}, 6 \% \mathrm{BCa}, \text { areia } \\
\text { SAG }\end{array}$ & 1,7 & 109 & 14,7 & 0,19 \\
\hline $\begin{array}{l}50 \% \mathrm{Cpt}, 6 \% \mathrm{BCa}, \text { areia } \\
\text { SAG }\end{array}$ & 2,0 & 151 & 14,9 & 0,33 \\
\hline $\begin{array}{l}30 \% \mathrm{Cpt}, 10 \% \mathrm{BCa} \text {, areia } \\
\text { SAG }\end{array}$ & 2,5 & 98 & 28 & 0,46 \\
\hline $\begin{array}{l}50 \% \mathrm{Cpt}, 10 \% \mathrm{BCa} \text {, areia } \\
\text { SAG }\end{array}$ & 3,0 & 154 & 24,4 & 0,47 \\
\hline $\begin{array}{l}30 \% \mathrm{Cpt}, 8 \% \mathrm{BNa} \text {, areia } \\
\text { SAG }\end{array}$ & 2,0 & 83 & 18,5 & 0,27 \\
\hline $\begin{array}{l}50 \% \mathrm{Cpt}, 8 \% \mathrm{BNa} \text {, areia } \\
\text { SAG }\end{array}$ & 2,7 & 113 & 17,7 & 0,34 \\
\hline $\begin{array}{l}30 \% \mathrm{Cpt}, 8 \% \mathrm{BCa}, \text { areia } \\
\text { SAG }\end{array}$ & 2,3 & 102 & 23,3 & 0,38 \\
\hline $\begin{array}{l}50 \% \mathrm{Cpt}, 6 \% \mathrm{BCa}, \text { areia } \\
\text { SAG }\end{array}$ & 2,6 & 138 & 19,9 & 0,42 \\
\hline $\begin{array}{l}30 \% \mathrm{Cpt}, 8 \% \mathrm{BNa} \text {, areia } \\
\text { SAF }\end{array}$ & 2,0 & 41 & 17,6 & 0,21 \\
\hline $\begin{array}{l}50 \% \mathrm{Cpt}, 8 \% \mathrm{BNa} \text {, areia } \\
\text { SAF }\end{array}$ & 2,5 & 54 & 17,3 & 0,28 \\
\hline $\begin{array}{l}30 \% \mathrm{Cpt}, 8 \% \mathrm{BCa} \text {, areia } \\
\text { SAF }\end{array}$ & 2,2 & 51 & 21,0 & 0,25 \\
\hline $\begin{array}{l}50 \% \mathrm{Cpt}, 6 \% \mathrm{BCa} \text {, areia } \\
\text { SAF }\end{array}$ & 2,7 & 67 & 19,6 & 0,29 \\
\hline $\begin{array}{l}50 \% \mathrm{Cpt}, 6 \% \mathrm{BNa} \text {, areia } \\
\text { SAG com } 60 \text { min. de } \\
\text { tempo de mistura }\end{array}$ & 2,0 & 165 & 17,6 & 0,36 \\
\hline $\begin{array}{l}50 \% \mathrm{Cpt}, 6 \% \mathrm{BCa} \text {, areia } \\
\text { SAG com } 60 \mathrm{~min} . \text { de } \\
\text { tempo de mistura }\end{array}$ & 2,1 & 195 & 19,0 & 0,42 \\
\hline
\end{tabular}


PICANÇO, M.S.; ANGÉLICA, R.S.; BARATA, M.S. revista Matéria, v.19, n.02, pp. 94-104, 2014.

\subsection{Análise das imagens no MEV}

Por meio da visualização no microscópio eletrônico de varredura foi possível identificar regiões de baixo (figuras 9a e 9b), e alto grau de adensamento (figuras 10a e 10b), no mesmo corpo de prova do ensaio de fluxibilidade Orlov.

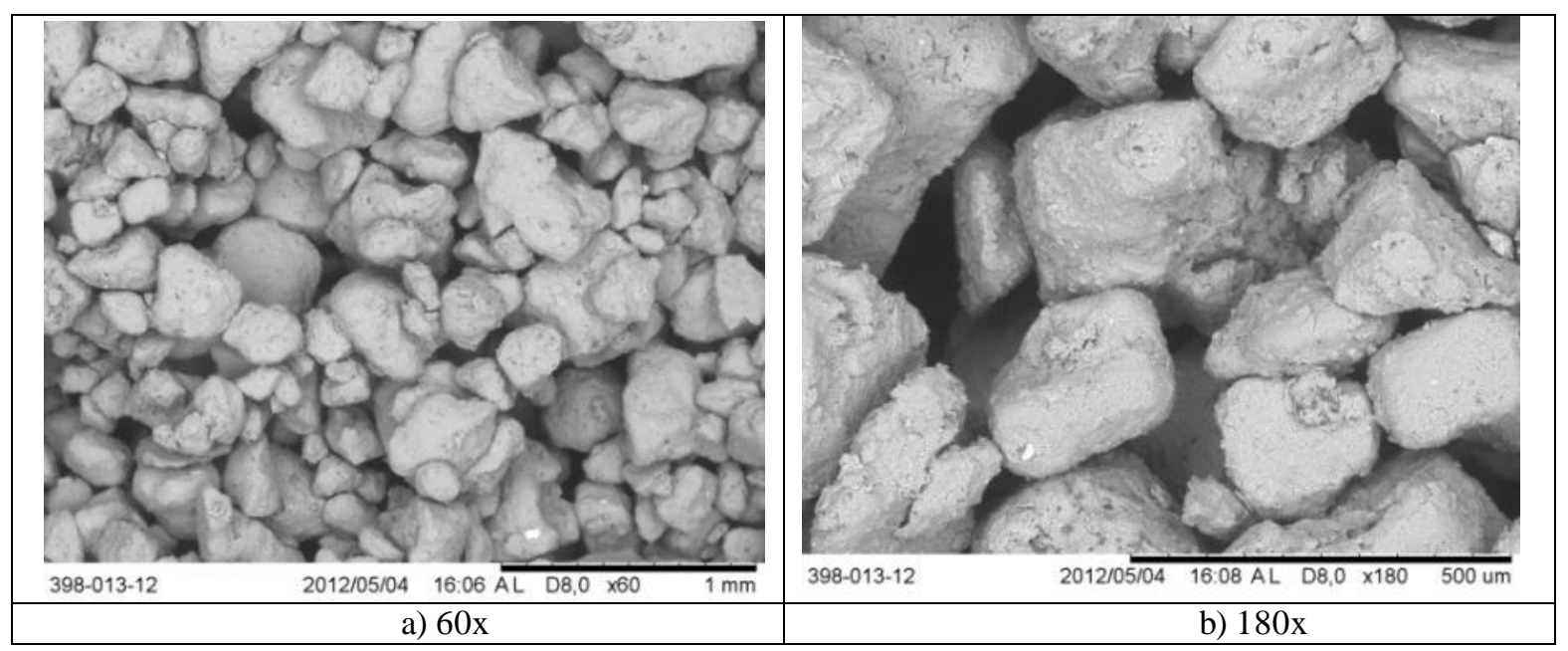

Figura 9: Imagens do MEV na região A do corpo de prova do ensaio Orlov mostrando menor contato entre os grãos de areia envolvidos por bentonita e pó de carvão com aumento de a) 60x e b) 180x.

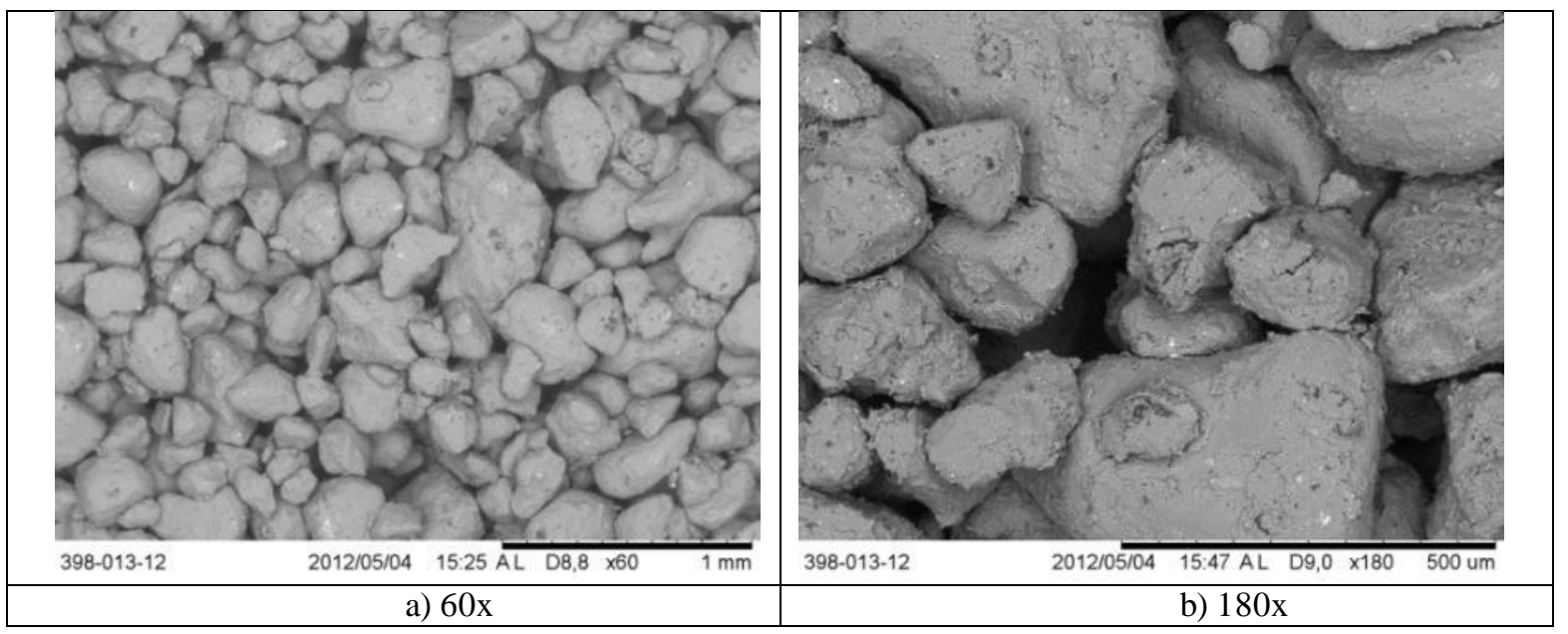

Figura 10: Imagens do MEV na região B do corpo de prova do ensaio Orlov mostrando maior contato entre os grãos de areia envolvidos por bentonita e pó de carvão com aumento de a) 60x e b) 180x.

\section{DISCUSSÃO}

O efeito do teor e tipo de bentonita visto na figura 4 demonstra que estas duas variáveis não parecem afetar a fluxibilidade TNO, apesar do aumento da adesão entre os grãos de areia. No entanto, teores crescentes de compactabilidade reduzem significativamente a escoabilidade sob queda da areia de moldagem. Esta mesma tendência foi obtida por Guesser, 1987, considerando este ensaio pouco sensível às mudanças de composição da mistura [9].

A influência da compactabilidade, teor e tipo de bentonita sobre a fluxibilidade Orlov podem ser observadas na figura 5. Os resultados indicam que a menor condição de fluxibilidade é obtida com o uso da bentonita sódica natural, maior compactabilidade e elevado teor de bentonita. De acordo com a literatura estas variáveis aumentam a força de coesão (entre a bentonita) e adesão (bentonita e grãos de areia) dificultando a movimentação dos grãos durante a aplicação da força de compactação [르, $\underline{8}]$. 
PICANÇO, M.S.; ANGÉLICA, R.S.; BARATA, M.S. revista Matéria, v.19, n.02, pp. 94-104, 2014.

A mesma tendência de redução da fluxibilidade sob compactação ocorre com a aplicação de areias mais finas. Ou seja, grãos de menor tamanho médio (maior módulo de finura) estão mais conectados em função da maior superfície de contato, elevando as forças de adesão e prejudicando o movimento da areia de moldagem durante a confecção dos corpos de prova, conforme é descrito na figura 6 [2].

Nota-se ainda, na figura 7, que a fluxibilidade Orlov diminui na medida em que se aumenta o tempo de mistura, pois desta forma eleva-se a plasticidade da areia a verde e, portanto, a força de ligação entre os grãos e a bentonita, restringindo o movimento da areia de moldagem [2] .

Com relação aos diferentes níveis de compactação, a figura 8 indica que com o aumento do grau de adensamento, eleva-se a fluxibilidade Orlov, pois é aplicada uma maior força de compactação para deslocar os grãos de areia. É importante ressaltar que a fluxibilidade sofre menor influência das propriedades da areia em corpos de prova confeccionados com alto grau de compactação, uma vez que a maior movimentação dos grãos compensa a redução de escoabilidade gerado pela força de ligação da bentonita [9].

Através das análises no microscópio de varredura, pode-se visualizar o menor contato entre os grãos de areia envolvidos por bentonita no ponto A, mostrado nas figura 9a e 9b, em relação ao ponto B, mostrado nas figuras 10a e 10b. Isto ocorre, porque na região de menor adensamento, a distância de deslocamento dos grãos necessária para compactar o corpo de prova é maior, dificultando o adensamento e tornando esta região mais porosa.

\section{CONCLUSÕES}

Os resultados experimentais obtidos revelaram que o ensaio TNO é sensível às mudanças de compactabilidade, sendo menor para altos teores desta. No entanto, este ensaio não possui correlação com as variações de quantidade e tipo de bentonita. Já o ensaio Orlov, que mede a fluxibilidade sob compactação, proporciona forte relação com as mudanças de composição, apresentando menores valores de escoabilidade quando utilizada elevada quantidade de bentonita sódica natural, maior compactabilidade, areias de maior módulo de finura (mais finas), elevado tempo de mistura e alto grau de compactação. Nota-se ainda que os corpos de prova com maior nível de adensamento sofreram menor influência das variações de composição em relação à fluxibilidade. É visto também que a escoabilidade sob compactação está diretamente vinculada à força de ligação da bentonita à areia, por restringir a movimentação dos grãos durante a compactação, quando utilizadas misturas com maior força de adesão e coesão.

\section{AGRADECIMENTOS}

O autor agradece à Tupy S.A. em especial aos Laboratórios de Areias/Metalúrgico e a UDESC pelo apoio durante a preparação deste artigo.

\section{REFERÊNCIAS BIBLIOGRÁFICAS}

[1] SCHIELE, F.; GMBH, S. "Primeiros passos para a simulação do processo de compactação do material de moldagem". Fundição e Serviços, v 14, n. 129, pp. 16 - 31, Set. 2003.

[2] MARIOTTO, C. L. Areias de moldagem aglomeradas com argila, São Paulo, IPT, 1978.

[3] GUESSER, W. L. Estudo sobre as bentonitas brasileiras em areia de moldagem. Tese de M. Sc., USP, São Paulo, SP, Brasil, 1982.

[4] BCIRA. “Green sand moulding technology”. BCIRA Journal, pp. 1-145, 1978.

[5] RADHAKRISHNAN, A. et al. "Effect of water - clay ratio and bentonita content on the flowability of synthetic sands", The British Foundryman, pp. 202-208, Set.1975.

[6] DISA TECHNOLOGIES. “Sand control by flexibility”. Disamatic Conventions, 1977.

[7] KLEIMANN, W. "Influência do carbono de processo sobre as propriedades de fluidez e compactação das areias aglomeradas com bentonita”. Fundição e Serviços, v 12, n. 105, pp. 18-23, 2001.

[8] LEVELINK, H. G.; BERG, H. “Das Mischen von tongebundenen Formsand”. In: GUESSER, W. L. Estudo sobre as bentonitas brasileiras em areia de moldagem, Tese de M.Sc., USP, São Paulo, SP, Brasil, 1982. 
PICANÇO, M.S.; ANGÉLICA, R.S.; B ARATA, M.S. revista Matéria, v.19, n.02, pp. 94-104, 2014. [9] GUESSER, W. L. "Fluxibilidade em areia de moldagem a verde". In: Simpósio de Processos de Fundição e Controle de Qualidade de Produtos Fundidos, Joinville, Santa Catarina, Brasil, Abril, 1987.

[10] ASSOCIAÇÃO BRASILEIRA DAS INDÚSTRIAS DE FUNDIÇÃO DE FERRO E AÇO - COMISSÃO DE ESTUDO DE MATÉRIAS PRIMAS, Determinação do teor de umidade, CEMP nº 105, 2003. [11] ASSOCIAÇÃO BRASILEIRA DAS INDÚSTRIAS DE FUNDIÇÃO DE FERRO E AÇO - COMISSÃO DE ESTUDO DE MATÉRIAS PRIMAS, Determinação da resistência à compressão a verde da mistura padrão, CEMP n60, 2003.

[12] ASSOCIAÇÃO BRASILEIRA DAS INDÚSTRIAS DE FUNDIÇÃO DE FERRO E AÇO - COMISSÃO DE ESTUDO DE MATÉRIAS PRIMAS, Determinação da resistência à tração a úmido da mistura padrão, CEMP n62, 2003.

[13] ASSOCIAÇÃO BRASILEIRA DAS INDÚSTRIAS DE FUNDIÇÃO DE FERRO E AÇO - COMISSÃO DE ESTUDO DE MATÉRIAS PRIMAS, Determinação da permeabilidade, CEMP nº 80, 2003. 